\title{
Is there a Correlation between being involved in an Accident and Violent Victimization?
}

\section{Salminen $S^{*}$}

Department of Social Psychology, University of Helsinki, Kari Haikonen, National Institute for Health and Welfare, Finland

*Corresponding author: Simo Salminen, Department of Social Psychology, University of Helsinki, Box 54, FI-00014 University of Helsinki, Finland, Tel: +358-400-700352; Email: simo.salminen@alumni.helsinki.fi

\section{Research article \\ Volume 1 Issue 3}

Received Date: October 25, 2017

Published Date: November 08, 2017

DOI: $10.23880 /$ eoij-16000120

\section{Abstract}

The aim of this study is to examine the link from victim's perspective. Criminological research had approached the link between crime and injury from the perspective of offenders as in the self-control theory of criminality. Based on the accident proneness theory, we suggest that a person involved in an accident is more likely to be a victim of violence. Our representative sample consisted of 7193 Finnish people over 15 years of age in 2009. Results showed that victims of violence were at a five-fold risk of being involved in a traffic accident and at more than a two-fold risk of sustaining accidents at work or at home compared to other. Our results support both theories.

Keywords: Crime; Injury; Self-Control Theory; Accident Proneness; Victimization; Violence

\section{Introduction}

\section{Self-Control Theory of Criminology}

Most of the available criminological research on the link between crime perpetration and accident proneness, or crime and injury, approaches this issue from the perspective of criminal offending [1]. In other words, studies have dealt with criminal offenders' above-average risk of suffering non-crime related accidents and injuries. Comparatively speaking, there is a lack of research on the link between the risk of being a victim of violence and the risk of non-crime related injury. However, an extensive body of research shows that committing criminal offences and criminal victimization are strongly associated. Indeed, it appears that no studies that have examined the offendingvictimization correlation, have failed to observe a strong correlation [2]. The link has also been confirmed in Finnish data [3]. People who are highly involved in crime tend to manifest criminal victimization that is clearly above average levels. This firm finding means that, empirical study of and theoretical reflection on the link between crime victimization and accident proneness may benefit from the lessons learned in the study of the offending-accident nexus.

In criminology, the link between accidents and crime perpetration has been discussed most thoroughly in the self-control theory of crime, as developed by Gottfredson and Hirschi [4]. According to this theory, self-control,- as a relatively stable personality feature explains individual-level variation in criminality. The self-control theory predicts that offenders are generalists: they tend to commit many types of offences rather than specialize in some particular type of crime. Similarly, crime itself is just one outlet for a broader behavioral tendency. Criminality was seen as a manifestation of a more general behavioural pattern that includes all kinds of impulsive, risky and costignoring activities. People with low self-control tend to be orientated toward the short-term gratification of needs, and lack perseverance [4].

The hypothesis that crime may be positively associated with accident proneness has been confirmed by multiple studies. A recent review of studies targeting children and adolescents observed that general risktaking behaviour was consistently associated with 


\section{Ergonomics International Journal}

injury, with a likelihood that was more than mere chance. Consistent with the generality hypothesis of the self-control theory, substance abuse was also associated with injuries [5]. Regarding the crime-accident link in general, Shepherd, Farrington and Potts [6] concluded that "it is clear that offending and antisocial behaviour are positively related to getting injured". They further suggested that both injury proneness and offending are consequences of having an antisocial personality, which remains fairly consistent from childhood to adulthood.

A recent study based on a longitudinal United Kingdom sample indicated that childhood externalizing behaviors were associated with an increased injury risk, ranging over a wide scope of injury types, including traffic, work and home injuries. In this study, measures of externalizing behaviors included hostility towards other children and adults, misbehavior, and mischief activities that can be described as childhood manifestations of delinquency. The link between externalizing behaviors and injuries reflected patterns of behaviour that are stable over the life course. The researchers also suggested that the link may be mediated by differential exposure to risky environments, thus combining trait and routine activity components in their explanation [7].

Previous research has determined relatively strong correlations between crime victimization and accidents in both crimes and non-crime related injuries. Furthermore, the association between being a victim of crime and injury is unlikely to be a culturally-specific phenomenon [8]. A correlation between accidents and criminal behaviour has been observed, for instance, among Canadian adolescents in cross-sectional surveys: youths who have been in accidents report more criminal behaviour than youths who have not been in accidents [1].

In terms of explanation, the link between crime and accident proneness is typically considered false in the sense that crime cannot be seen as a direct cause of non-crime related accidents, or vice versa. This has led researchers to search for a possible third factor that may account for the correlation. Some researchers identify this trait with Gottfredson and Hirschi's [4]concept of (low) self-control, while others prefer notions of antisocial personality or stable behavioural propensity [6], and stimulation-seeking [9], sometimes combined in reference to routine activities [7]. Social control theory has also received some support in the analysis of the crime-accident link. Based on their study of a Canadian youth sample, Junger and Tremblay [1] observed that in a juvenile population, low social control (low supervision) contributes to both high delinquency and high accident risk, creating a false link between the two.

The above discussion of the studies on the offending- accident link raises the question of whether or not similar mechanisms are at play in the link between violent victimization and non-crime related accident proneness. As far as we know, there is a comparative lack of research on the crime-accident link from the point of view of victimization, as opposed to offending. Then we analysed based on the theory of accident proneness and risk-taking associations between being a victim of violent act and with various types of noncrime related injuries. At last we studied the effect of gender and age on the relationship between being a victim of violence and injury involvement. Our research thus adds to prior work on the crime-accident link by focusing on the victim perspective.

\section{The Theory of Accident Proneness}

The first scientific theory that attempted to explain accidents was the theory of accident proneness. Greenwood and Woods [10] insisted that "accidents occur to a limited number of individuals who have a special susceptibility to accidents". The theory assumed that accident proneness was a stable personality trait, and that some people have an inherent tendency to be involved in accidents [11]. One interpretation of the accident proneness theory is the assumption that a person involved in an accident is more likely to encounter violence. Perhaps accident-prone people tend to repeatedly encounter hazardous situations, including crimes of violence.

The theory of accident proneness has been criticized on both theoretical and empirical grounds. The studies published have caused conceptual confusion, because the concept of accident proneness is used as a personality trait, a general characteristic, an innate characteristic, or an explanatory concept [12]. Statistical criticism of the accident proneness theory concludes that the risk of being involved in an accident varies within a population [13], whereas earlier studies assumed the homogenous exposure to injuries.

Another hypothesis regarding the relationship between accidents and violence has arisen from risktaking theories. The risk compensation theory assumes that people are ready to accept a constant level of risk. If the risk level decreases due to safety measures (e.g. seat belts in cars), people tend to adjust their goals (e.g. try to arrive sooner at their destination), so that the risk level returns to what it was before the measure. The effects of the safety measures are thus eliminated in the long run [14]. Because the assumption of full compensation has been criticized, the concept of risk compensation has now been replaced by the concept of behavioral adaptation [15]. The risk compensation theory allows us to ask whether or not, when the accident risk in one area of life is decreased by a safety measure (e.g. the use of safety gloves at work), people take more risks in other areas of life (e.g. driving at 


\section{Ergonomics International Journal}

higher speed).

\section{The Aim}

The aim of this article is to examine whether the risk of violent victimization is generally related to injuries. Based on the above mentioned two theories we present the following hypotheses:

- The self-control theory of criminal behaviour leads to the prediction that victims of violence are at an above-average risk of accidents

- Based on the risk compensation theory we assume highly negative associations between involvements in accidents and encounters of violence, because people involved in accidents take less risks, which leads to a lower risk of violence victimization or vice versa.

\section{Methods}

\section{Sample}

National victimization surveys look at the number of people in the Finnish population aged 15 and over who have been victims of accidents and violence. These surveys were conducted in 1980, 1988, 1993, 1997, 2003, 2006, and 2009. Older samples are collected by different institutions (Statistics Finland) and they are not possible to use. That is why we used the latest research sample (2009) in this article. It was taken from the Population Registry of Finland, and represents the entire population aged $15+$. It consisted of 9576 people, of which 7193 (3 445 men and 3748 women), or 75\%, were interviewed. A total of 6723 were aged 15-74, and 470 were aged 75 or over. The response rate was $75.1 \%$. Response was voluntary and based on informed consent.

The Swedish-speaking minority was interviewed in Swedish. The sample was representative of both the Finnish- and Swedish-speaking population, but not those who spoke other languages as their mother tongue. Gender and age were used as demographic factors, because they were involved in injuries in different ways [16]. Participants were divided under and over 40 years of age based on the uniform sampling function. Violence was selected as type of crime, because it concerns a person as physical phenomenon like injuries.

\section{Measurements}

The content of the interview was planned by an expert group from several Finnish research institutes (Statistics Finland, National Institute for Health and Welfare, Finnish Institute of Occupational Health), and covered all kinds of accidents and violence. The data were collected through computer-assisted telephone interviews, the average length which was 15 minutes. The total number of questions was 204, of which 8 was used in the analyses for this article. Professional interviewers from Statistics Finland conducted the interviews from March to June, and August to October in 2009.

The participants were asked to report all the accidents they had suffered in the previous 12 months. A home accident was defined as an injury-causing accident that took place at home, in one's own yard, or in a building in the yard. A sports accident was an accident that happened while the victim was engaged in either unorganized or organized athletic activity. An injury that happened at the workplace of the victim or on the way to or from work was classified as an occupational accident. An accident was defined as a traffic accident if at least one vehicle was involved. It can include also commuting traffic accidents. Other accidents covered the remaining accidents, such as falling while shopping, or being injured while being engaged in a hobby other than sports [17]. Violence or the threat of violence was defined as obstruction of moving, being pushed, being stuck, being hit, violence with a weapon, sexual violence, and other physical violence causing physical injury [18]. Because the aim of this survey is to chart the number of accidents and violent acts, the severity of the accidents and violence was not elicited, but all injuries had to involve physical injury to qualify.

\section{Analyses}

The Statistical Analysis System (SAS 9.1) and R software for statistical computing were used for statistical analysis. Means, frequencies, two-way crosstabulations, correlations and odds ratios were calculated for each kind of accident and act of violence. We analysed the association between accident involvement and being a victim of violence by logistic regression analysis, using accident-free participants as a reference group.

\section{Results}

Of all participants $6.7 \%$ were involved in sport accidents, $6.4 \%$ home accidents, $4.4 \%$ occupational accidents, $1.6 \%$ traffic accidents, and $2.7 \%$ other accidents. In addition, $1.7 \%$ of the respondents have been victims of violence. These numbers are rather high, but they include also minor accidents.

Table 1 presents the prevalence of violence victimization by accident experience in percentages. Of those who suffered traffic accidents, $8.6 \%$ were also victims of violence. The percentages were lower for occupational accidents (4.1\%), home accidents (3.3\%), sports accidents (3.1\%) and other (3.1\%) accidents. The associations between violence victimization and accidents were near zero level, because less than $1 \%$ of the participants were victims of both accidents and violence during the same period of time. 


\section{Ergonomics International Journal}

Table 1 shows that respondents involved in accidents were at a significantly higher risk of being victims of violence than those not involved in accidents. The odds ratio was highest (5.6) for traffic accidents. Victims of home, work and any accidents experienced violence over twice more often than respondents who were not involved in accidents. Those injured in sports activities encountered violence significantly more often than those not involved in sports accidents. The odds ratio for other accidents was not significant. The odds ratio for violence was 2.6, when it was explained as suffering any accident. Thus, people who suffered accidents were also at an elevated risk of being victims of violence.

\begin{tabular}{|c|c|c|c|c|}
\hline \multirow{2}{*}{ Accident } & \multicolumn{3}{|c|}{ Victim of violence (\%) } & \multirow{2}{*}{ Odds ratio (95\% CI) } \\
\cline { 2 - 5 } & No accident & Accident & All respondents (N) & $5.63(2.87-11.07)$ \\
\hline Traffic & 1.6 & 8.6 & 116 & $2.47(1.37-4.44)$ \\
\hline Work & 1.6 & 4.1 & 317 & $2.17(1.25-3.76)$ \\
\hline Home & 1.6 & 3.3 & 459 & $1.88(1.08-3.25)$ \\
\hline Sports & 1.6 & 3.1 & 481 & $1.96(0.85-4.51)$ \\
\hline Other & 1.7 & 3.1 & 193 & $2.57(1.77-3.72)$ \\
\hline Any context & 1.3 & 3.4 & 1372 & \\
\hline
\end{tabular}

Table 1: Prevalence of violent victimization by accident type, and odds ratio, Finland 2009.

$\mathrm{N}$ for "no accident" varied between 6712 and 7077, for "Accident" between 116 and 481 with the exception of the "Any context" row where $\mathrm{N}=5821$ and 1372.

Odds ratios from logistic regression equation regressing violent victimization on accident (reference category = "No accident").

We also fitted an 'any accident' model for males and females separately. The results indicated that the association between encountering violence and accidents was a little stronger for females than for males (Table 2). It seems that the association was also stronger for participants over 40 years of age than for those who were younger.

\begin{tabular}{|c|c|}
\hline Group & Odds ratio (95\% CI) \\
\hline \multicolumn{2}{|c|}{ Gender } \\
\hline Female (N=3 748) & $2.62(1.54-4.43)$ \\
\hline Male (N=3 445) & $2.53(1.48-4.24)$ \\
\hline \multicolumn{2}{|c|}{ Age } \\
\hline Under 40 (N=2 566) & $2.19(1.38-3.47)$ \\
\hline Over 40 (N=4 627) & $2.40(1.27-4.53)$ \\
\hline
\end{tabular}

Table 2: Association between violence and any accidents in gender and age groups, Finland 2009

Ps. Violence is used as a dependent variable and accidents as an independent variable.

\section{Discussion}

Previous studies have shown that criminal offending and crime victimization are strongly associated: we now add the connection between crime victimization, more specifically violence victimization, and involvement in accidents. We can conclude that victims of crime are also at an extended risk of being involved in an accident.

The self-control theory of crime [4] insists that criminal offending increases the risk of involvement in accidents. We have added the perspective of crime victimization to this theory, and assumed that victims of crime- in our study, of violence - are at a higher risk of accidents. The results of our study supported this assumption, because victims of violence were more often involved in accidents than those who had not involved in injuries. However, in this kind of crosssectional design, it is not possible to assess the causal relations between encountering violence and being involved in an accident.

It is possible that some personality factors (low selfcontrol, risk taking or antisocial personality) may be behind the link between violence victimization and being involved in accidents. However, in our data, based on a large population survey, we are unable to measure these personality traits, because they would have required a great deal of items and a psychologist to interpret the responses.

Our results showed positive connections between involvement in accidents and encounters of violence. The assumption regarding the positive link between suffering accidents and being a victim of a crime based on the accident proneness was confirmed. However, the results did not support the assumption based on the risk compensation theory, which require high negative correlations between accidents and violence.

The strongest association was found between violence victimization and traffic accidents. This is perhaps due to the same group of high risk- young men [16]. The connection was lower between, for example, being a victim of violence and home accidents, because older women are a group at risk of home accidents but not of violence.

On an empirical level, the results of this study were in 
line with a previous study which showed zero correlations between different types of injuries [16]. The associations between crime victimization and accidents were rather weak. However, the connection was slightly stronger among women than among men. It seems that the association between crime victimization and being involved in accidents was slightly stronger among older than younger people, because the risk of being a victim of crime and being involved in an accident is higher among younger than older people [16].

The main drawback of this study is that the information collected from the interviewees was retrospectively. Participants were asked to report their accidents and violent encounters from the past 12 months, which is the usual follow-up time in injury research. But this reference time is too long, as people forget about $30 \%$ of their injuries in one year [19]. On the other hand, too short a reference time may produce too small number of injuries and violent acts. This was a cross-sectional study, when injuries and violent encounters were measured at the same time. That is why it is not possible to determine the causality between injuries and violent acts.

The third drawback is that $25 \%$ of the sample did not participate in this study. Analysis of non-response showed that young men declined the interview invitation more often than older people. This is problematic, because young men are in the risk group for traffic, sport and work accidents [16] and they also encounter violence more often than other groups [18]. If they had participated in this study, the relationships between accidents and violence may have been somewhat higher. However, we did only study victimization of violent crimes, and not crimes involving property.

The most important contribution to criminal theory of this article is that it adds the perspective of the victim of the violent act to the link between criminal offences and accidents. The results confirmed the self-control theory of crime [4]. The positive connection between accidents and encounters of violence confirmed our interpretation of the accident proneness theory. However, the risk compensation theory was not confirmed, because high negative associations between injury involvement and being a victim of violent act were not found.

In the future, research should focus on the personality of victims of violence. The self-control theory of crime [4] assumes that a lack of self-control predicts the variation in criminality. There is no similar theory about victims. On the other hand, the association between crime victimization and accident involvement could vary by the personality of victim [11].

\section{References}

1. Junger M, Tremblay RE (1999) Self-control, accidents and crime. Crim Just Behav 26(4): 485501.

2. Lauritsen JL, Laub JH (2007) Understanding the Link between Victimization and Offending: New Reflections on an Old Idea. In: Hough M \& Maxfield M (Eds.), Surveying Crime in the 21st Century. Crime Prevention Studies, Willan Publishing, London, UK, pp: 55-75.

3. Keinanen A (2009) Nuorten rikoskayttaytymisen ja uhriksi joutumisen valinen suhde. In: Salmi V (Ed.), Nuorten rikoskayttaytyminen ja uhrikokemukset. Oikeuspoliittisen tutkimuslaitoksen tutkimuksia 246. National Research Institute of Legal Policy, Helsinki.

4. Gottfredson MR, Hirschi T (1990) A General Theory of Crime. Stanford University Press, Stanford, CA, USA.

5. Mytton J, Towner E, Brussoni M, Gray S (2009) Unintentional injuries in school-aged children and adolescents: lessons from a systematic review of cohort studies. Inj Prev 15(2): 111-124.

6. Shepherd J, Farrington D, Potts J (2002) Relations between offending, injury and illness. J Royal Soc Med 95(11): 539-544.

7. Jokela M, Power C, Kivimaki M (2009) Childhood problem behaviors and injury risk over the life course. J Child Psychol Psychiatr 50(12): 15411549.

8. Kivivuori J (2008) Rikollisuuden syyt [Causes of crime]. Nemo, Helsinki, Finland.

9. Raine A, Reynolds C, Venables PH, Mednick SA, Farrington DP (1998) Fearlessness, stimulationseeking, and large body size at age 3 years as early predispositions to childhood aggression at age 11 years. Arch Gen Psychiatr 55(8): 745-751.

10. Greenwood M, Woods HM (1919) The incidence of industrial accidents upon individuals with special reference to multiple accidents. Medical Research Committee, Industrial Fatigue Research Board. Her Majesty's Stationery Office, London.

11. Shaw L, Sichel HS (1971) Accident proneness. $1^{\text {st }}$ (Edn.), Pergamon Press, Oxford.

12. McKenna FP (1983) Accident proneness: a conceptual analysis. Accid Anal Prev 15(1): 65-71. 


\section{Ergonomics International Journal}

13. Surry J (1969) Industrial accident research: A human engineering appraisal. University of Toronto, Department of Industrial Engineering, Toronto pp: 179-197.

14. Peltzman S (1975) The effects of automobile safety regulation. J Pol Econ 83(4): 677-725.

15. Trimpop RM (1996) Risk homeostasis theory: Problems of the past and promises for the future. Saf Sci 22: 119-130.

16. Salminen S, Heiskanen M (1997) Correlations between traffic, occupational, sports and home accidents. Accid Anal Prev 29(1): 33-36.
17. Heiskanen M, Aromaa K, Niemi H, Ruusinen A, Sirén $\mathrm{R}$ (1991) Accidents and violence 1988. National Research Institute of Legal Policy, Publication No. 108. Central Statistical Office of Finland, Helsinki.

18. Sirén R, Aaltonen M, Kaariainen J (2010) Suomalaisten vakivaltakokemukset 1980-2009. Kansallisen uhritutkimuksen tuloksia Oikeuspoliittisen tutkimuslaitoksen tutkimustiedonantoja 103. National Research Institute of Legal Policy, Helsinki.

19. Elander J, West R, French D (1993) Behavioral correlates of individual differences in road-traffic crash risk: an examination of methods and findings. Psychol Bull 113(2): 279-294. 